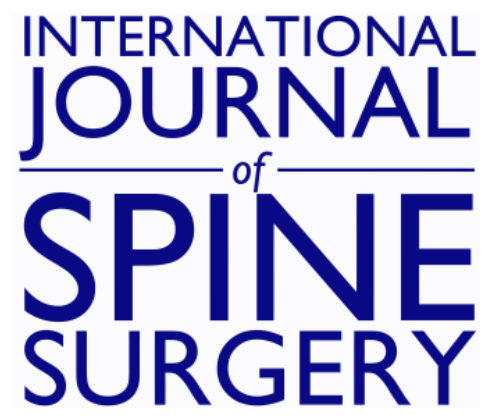

\title{
Preoperative embolization versus local hemostatic agents in surgery of hypervascular spinal tumors
}

Dmitry Ptashnikov, Nikita Zaborovskii, Dmitry Mikhaylov and Sergei Masevnin

Int J Spine Surg 2014, 8 ()

doi: https://doi.org/10.14444/1033

http://ijssurgery.com/content/8/33

This information is current as of April 26, 2023.

Email Alerts Receive free email-alerts when new articles cite this article. Sign up at:

http://ijssurgery.com/alerts

The International Journal of Spine Surgery

2397 Waterbury Circle, Suite 1,

Aurora, IL 60504, Phone: +1-630-375-1432 


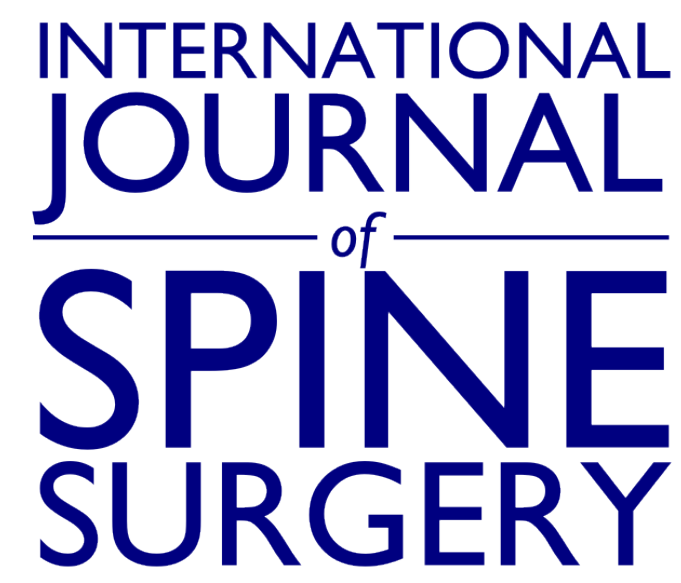

This article generously published free of charge by the International Society for the Advancement of Spine Surgery.

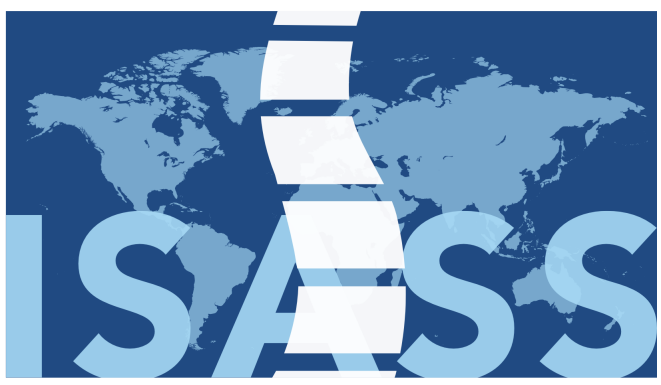

INTERNATIONAL SOCIETY for the ADVANCEMENT of SPINE SURGERY 


\section{Preoperative embolization versus local hemostatic agents in surgery of hypervascular spinal tumors}

Dmitry Ptashnikov, MD, PhD, Nikita Zaborovskii, MD, Dmitry Mikhaylov, MD, Sergei Masevnin, $M D$

Vreden Russian Research Institute of Traumatology and Orthopedics Spinal Surgery and Oncology

\section{Abstract}

\section{Background}

Currently, there is no consensus about how to reduce the intraoperative risk of hemorrhage in spinal decompression surgery of hypervascular spinal tumors, such as aggressive hemangioma, multiple myeloma, plasmacytoma, metastasis of renal cell carcinoma.

\section{Methods}

A retrospective study of 110 patients, operated in our institute was held in the period between 2003 and 2013. There were 69 male and 41 female patients with extradural hypervascular spinal tumor. The study included 61 patients with metastasis of renal cell carcinoma, 27 with multiple myeloma, 15 with plasmacytoma and 7 with aggressive hemangioma.

The first group included 57 patients who underwent preoperative tumor embolization. The second group consisted of 53 patients, which were treated surgically using intraoperative local hemostatic agents. We performed 2 types of treatment options: palliative decompression and total spondylectomy. The first group was divided into two subgroups: 30 patients with palliative decompression (1PD) and 27 with total spondylectomy (1TS). In the second group there were: 28 patients with palliative decompression (2PD) and 25 with total spondylectomy (2TS). The parameters under evaluation were the blood loss volume, drainage loss, operation time, hemoglobin level, possible complications and time of hospital stay.

\section{Results}

The average intraoperative blood loss for all embolized patients was slightly less than in subgroups with local hemostatic agents. No significant difference in blood loss volume was found between groups $1 \mathrm{PD}$ and $2 \mathrm{PD}(\mathrm{p}>0.05)$. In groups $1 \mathrm{TS}$ and $2 \mathrm{TS}$, we did get significant difference $(\mathrm{p}<0.05)$. 
Statistically significant difference in the average drainage loss was found between two methods of hemostasis in both subgroups $(\mathrm{p}<0.05)$. The operation time was not significantly different between groups. Postoperative hemoglobin level reduce is almost equal in both groups of patients. Postoperative complications were also nearly equal in the groups. The average hospital stay was significantly less $(p<0.05)$ in groups with $2 \mathrm{PD}$ and 2TS.

\section{Conclusions}

The research proves that for patients with hypervascular spinal tumors, who underwent palliative decompression, there is no significant difference between two methods of reducing blood loss. Therefore, we do not see reasons to use expensive and risky procedure of embolization for such patients. While for patients with total spondylectomy preoperative embolization is efficient to reduce intraoperative bleeding.

keywords: tumors, blood loss, embolization, local hemostatic agents, decompression

Volume 8 Article 33 doi: 10.14444/1033

\section{Introduction}

In spinal tumors treatment, the surgical intervention aims toward decompression, either by direct removal of metastatic tissue or indirectly by palliative posterior laminectomy. These operations can be usually performed without any major bleeding problem. After meta-analysis of 18 papers, Chen et al. reported average estimated perioperative blood loss to be $2180 \mathrm{ml}^{1}$

Currently, there is no consensus about how to reduce the intraoperative risk of hemorrhage in spinal decompression surgery of hypervascular spinal tumors, such as aggressive hemangioma, multiple myeloma, plasmacytoma, metastasis of renal cell carcinoma. Major intraoperative blood loss in spine surgery is associated with an increased risk for surgical site infection ${ }^{2,3}$ and it also causes multiple end organ damage including spinal cord ischemia, thus, potentially is associated with poor surgical outcome. $^{4}$

Hypotensive anesthesia, careful tissue handling, hemostasis during surgery, and minimizing operative duration can help control blood loss. Measures routinely used to minimise blood loss include the assessment and correction of coagulopathy; the use of antifibrinolytic drugs, such as tranexamic acid; prevention of hypothermia; intraoperative ligation of feeding vessels; the use of bipolar electrocautery. ${ }^{1,5}$

The diagnosis of spinal tumors may represent an advanced stage of disease and patients undergoing surgery for a spinal tumor are often elderly, with compromised cardiovascular status, impaired immune system and poor physiological reserves, all of which render them more susceptible to the complications of intraoperative blood loss and transfusion. ${ }^{1,6}$ 
Treatment of hypervascular spine tumors is challenging as surgeons may experience profuse intraoperative bleeding which is difficult to control. ${ }^{7}$ Intraoperative hemorrhage can be sometimes massive in patients with hypervascular spinal tumors, especially in radical resection such as total en bloc spondylectomy. ${ }^{8}$

The use of selective arterial embolization to treat bone tumors was first described in 1975 by Feldman et al. ${ }^{9}$ Several case series have described the technical aspects of vertebral tumor embolization and suggested benefits of preoperative embolization on decreasing perioperative blood loss. ${ }^{10-13}$ However, it is doubted that embolization has no alternatives.

The use of local agents to achieve hemostasis is an old and complex subject in surgery and active used in neurosurgery since early 20th century. ${ }^{14,15}$ Although many new materials are presented each year, the best hemostatic agents have been the same for several decades. When applied topically, these agents can effectively control diffuse intraoperative bleeding. However, the appropriate use of haemostats requires a certain understanding of their advantages, limitations and the nature of complications associated with their application. ${ }^{16-18}$

Therefore, the purpose of our research was to compare the effectiveness of using different methods in reducing blood loss.

\section{Material and methods}

The total number of 110 patients (average age of 56.2 years) were operated in our institute in the period between 2003 and 2013. The analysis included a retrospective evaluation of patients cards. There were 69 male and 41 female patients with extradural hypervascular spinal tumor. There were 56 patients with metastasis of renal cell carcinoma, 32 with multiple myeloma, 15 with plasmacytoma and 7 with aggressive hemangioma in the study. The single-level tumor lesions were mainly located in the thoracic spine ( $\mathrm{n}=74$; $67.3 \%)$ and less percentage in lumbar spine $(n=36 ; 32.7 \%)$.

We decided to evaluate possible parameters in a surgically homogeneous group of patients (Table 1).

Table 1. Patients' demographic data.

\begin{tabular}{|l|l|l|l|l|}
\hline & \multicolumn{2}{|l|}{ Group 1 } & \multicolumn{2}{l|}{ Group 2 } \\
\hline Total & Subgroup 1PD & Subgroup 1TS & Subgroup 2PD & Subgroup 2TS \\
\hline Age & 30 & 27 & 28 & 25 \\
\hline Sex & $53.8 \pm 16.5$ & $54.6 \pm 11.2$ & $55.8 \pm 9.6$ & $57.9 \pm 15.6$ \\
\hline Histology type & Male, 24; Female, 6 & Male, 11; Female, 16 & Male, 20; Female, 8 & Male, 14; Female, 11 \\
\hline Aggressive hemangioma & 0 & & & \\
\hline Renal cell carcinoma & $22(20 \%)$ & $13(11.8 \%)$ & $16(14.6 \%)$ & $5(2.7 \%)$ \\
\hline Multiple mieloma & $8(7.3 \%)$ & $4(3.6 \%)$ & $12(10,9 \%)$ & $8(7.3 \%)$ \\
\hline
\end{tabular}




\begin{tabular}{|l|l|l|l|l|}
\hline Plasmacytoma & 0 & $6(5.5 \%)$ & 0 & $9(8.2 \%)$ \\
\hline Location & \multicolumn{5}{|l|}{} & & \\
\hline Thoracic spine & 15 & 22 & 18 & 19 \\
\hline Lumbar spine & 15 & 5 & 10 & 6 \\
\hline Procedure & Angiography + embolization & Gelatin-thrombin matrix \\
\hline Method & Laminectomy & Spondylectomy & Laminectomy & Spondylectomy \\
\hline Operation & & & \\
\hline
\end{tabular}

To analyze the impact on blood loss, we compared the following groups of patients: 57 patients who underwent preoperative transcutaneous spinal angiography and tumor embolization (gelatin sponge particles), 1-2 days prior operation ( $\mathrm{n}=51-1$ day, $\mathrm{n}=6-2$ days before). The second group consisted of 53 patients, which were treated surgically using intraoperative local hemostatic agents (gelatin-thrombin matrix). Local hemostatic agents were used only in this group.

Using the surgical principles, according to the Enneking classification, we performed 2 types of treatment options. The first is palliative considerations by wide decompressive laminectomy and percutaneous stabilization for patients with poor life expectancy, who expected the likelihood of improving the quality of life. The second is total spondylectomy with transpedicular stabilization using a posterior approach for thoracic spine or 2-stage combined approach for lumbar spine if a patient has good prognostic factors.

In the first group there were two subgroups: 30 patients with palliative decompression (1PD) and 27 with total spondylectomy (1TS). In the second group there were: 28 patients with palliative decompression (2PD) and 25 with total spondylectomy (2TS).

The inclusion criteria to the study were: the data of patients with hypervascular spinal tumors, spinal cord compression. The exclusion criteria to the study included: patients with preoperative anemia $(<12 \mathrm{~g} / \mathrm{dL})$, long postembolization time ( $>3$ days), coagulopathy.

The parameters under evaluation were the blood loss volume, drainage loss, operation time, hemoglobin level, possible complications and time of hospital stay. The double group comparisons were done by using independent sample Student t-test. A p-value of less than 0.05 was accepted as significant.

\section{Results}

The average intraoperative blood loss for all embolized patients was $1175 \mathrm{~mL}$ (range, 400-1700 mL) in subgroup 1PD, $3012 \mathrm{~mL}$ (range, 1750-4900 mL) in subgroup $1 \mathrm{TS}$ and it was slightly less than average in subgroups with local hemostatic agents: 2PD - 1557 $\mathrm{mL}$ (range, 600-2400 mL), 2 TS - $3262 \mathrm{~mL}$ (range, 1200-5600 mL). Nevertheless, no statistically significant difference in blood loss volume was found between groups of 
patients who underwent palliative decompression ( $p>0.05$ ). In groups of patients with total spondylectomy, results confirmed a high effectiveness of preoperative embolization, as we did get significant difference $(\mathrm{p}<0.05)$.

Drainage loss was $968 \mathrm{~mL}$ (range, $680-1400 \mathrm{~mL}$ ) in group 1PD compared to $464 \mathrm{~mL}$ (range, 310-660 mL) in group 2PD and $1223 \mathrm{~mL}$ (range, $700-1780 \mathrm{~mL}$ ) in in group 1TS compared to $983 \mathrm{~mL}$ (range, $650-1900 \mathrm{~mL}$ ) in group 2TS. Statistically significant difference in the average drainage loss was found between two methods of hemostasis in both subgroups $(\mathrm{p}<0.05)$.

Postoperative hemoglobin level reduce is almost equal in both groups of patients. The comparisons of the hemoglobin level are summarized in Table 2.

Table 2. Results.

\begin{tabular}{|l|l|l|l|l|l|l|}
\hline & Subgroup 1PD & Subgroup 2PD & p-value & Subgroup 1TS & Subgroup 2TS & p-value \\
\hline Blood loss (ml) & $1175 \pm 330$ & $1557 \pm 672$ & 0.139 & $3012 \pm 780$ & $3262 \pm 864$ & $0.042^{*}$ \\
\hline Drainage loss (ml) & $968 \pm 411$ & $464 \pm 127$ & $0.008^{*}$ & $1223 \pm 511$ & $983 \pm 331$ & $0.045^{*}$ \\
\hline Operative time (min) & $176 \pm 33$ & $184 \pm 26$ & 0.203 & $340 \pm 73$ & $334 \pm 46$ & 0.205 \\
\hline Hemoglobin level & \multicolumn{1}{|l}{} & & & & & \\
\hline Preoperative (g/dL) & $13.65 \pm 0.84$ & $13.32 \pm 0.94$ & 0.342 & $13.6 \pm 1.42$ & $13.56 \pm 0.96$ & 0.081 \\
\hline 1 day postoperative (g/dL) & $10.78 \pm 1.4$ & $10.04 \pm 1.93$ & 0.265 & $10.83 \pm 1.72$ & $11.96 \pm 1.21$ & 0.092 \\
\hline 1 week postoperative (g/dL) & $12.01 \pm 1.21$ & $12.04 \pm 1.04$ & 0.934 & $11.23 \pm 1.29$ & $12.1 \pm 0.54$ & 0.07 \\
\hline * & & & & & \\
\hline
\end{tabular}

Postoperative complications were also nearly equal in the groups (Table 3 ). While in the group 1PD, a patient developed irreversible neurologic deficits after embolization (Frankel D to A). Although preoperative embolization is a relatively safe procedure, there still remains risk of cord ischemia.

Table 3. Complications and hospital stay.

\begin{tabular}{|l|l|l|l|l|l|l|}
\hline & Subgroup 1PD & Subgroup 2PD & p-value & Subgroup 1TS & Subgroup 2TS & p-value \\
\hline Hematoma (reoperative cases) & 1 & 2 & 3 & 1 & \\
\hline Infection (reoperative cases) & 1 & 1 & 2 & 1 & 0 & \\
\hline Neurological deficit (cases) & 1 & 0 & & 1 & $0.049 *$ \\
\hline Hospital stay (days) & $32.6 \pm 10$ & $27.2 \pm 7.2$ & $0.012 *$ & $39.4 \pm 20.5$ & $36.5 \pm 5.7$ & \\
\hline
\end{tabular}

*significant difference between groups

The average hospital stay was significantly less $(p<0.05)$ in groups with local hemostatic agents (2PD, 2TS) compared to groups with embolization. The length of hospital stay in embolized groups was longer due to longer preoperative period. It was mainly affected by queuing to angiography. 


\section{Discussion}

Bleeding and blood loss in surgery of hypervascular spinal tumors is an important problem. The majority of orthopedic surgeons believe that vertebral body replacements became feasible with the introduction of modern embolization techniques. Preoperative tumor embolization is a standard for surgery of hypervascular spinal tumors. ${ }^{19-23}$ Nonetheless, not all sources of intraoperative bleeding can be controlled by means of arterial embolization. Difficulties in accessing the operation field and networks of venous structures and technical problems provide a small residual risk of massive hemorrhage even if the tumor itself is completely excluded from the arterial circulation. ${ }^{24}$ Moreover, embolization creates a window of ischemia in which the patient has tissue thromboplastin and necrotic tissue factors mobilized into their inflammatory milieu that can enhance the risk of disseminated intravascular coagulation. ${ }^{25}$

A few studies have showed wide divergence of intraoperative blood loss after embolization and decompression laminectomy. Kato et al. reported that intraoperative blood loss after preoperative embolization was twice less than in group without preoperative embolization. ${ }^{26} \mathrm{Schmidt}$ et al. concluded that for patients with tumor reduction, who underwent preoperative embolization, mean blood loss was $2350 \mathrm{~mL}^{27}$ Robial et al. showed average blood volume in suction, for patients with embolization in group with renal cell carcinoma, was $1175 \mathrm{~mL} .{ }^{28} \mathrm{We}$ found no statistically significant association between the two methods in subgroups (1PD and 2PD) where palliative decompression was performed. It is possible, conducting palliative considerations, the indications for embolization of hypervascular tumors could be reconsidered in the future, as local hemostatic agents provide adequate control of bleeding. Rejection from additional invasive procedure will reduce the surgical risks for oncology patients who are often in poor general condition. In the subgroups (1TS and 2TS) where total spondylectomy was performed difference between the two methods was statistically significant, local hemostatic agents did not provide adequate blood loss control. If we plan total spondylectomy, the use of preoperative embolization is recommended to reduce the risk of excessive intraoperative blood loss. However, Eck et al. said that if an en bloc extralesional resection is planned, preoperative embolization may not be necessary. ${ }^{25}$

Hemoglobin level. There were no significant differences between the groups in the first postoperative day and week. As a result, it was not possible to obtain informative data about hemoglobin level.

The operation time, which could be potentially associated with the invasiveness of surgery, was not significantly different between groups. In our results operation time was similar to other studies. ${ }^{26,29}$

Poor postoperative hemostasis may develop wound hematomas. Accumulation of blood in the wound causes the risk of infectious complications. ${ }^{30}$ It was proved that drainage loss was significantly less in the subgroups (2PD and 2TS) where intraoperatively local hemostatic agents was used. Better local hemostasis after local hemostatic agents is possible explanation. There were cases of revision operations caused by hematomas in these series of patients, but their number and distribution in groups could not estimated. 
Some experimental studies showed no neurological complications after ligation or embolization of 3-5 pairs of arteries which may supply spinal cord arteries. ${ }^{31-33}$ However, blood supply to the spinal cord has different variants of vascular network structures, and in some borderline cases there is a risk of ischemia. Hence the development of angiography equipment, improvement of quality and algorithms of intraoperative imaging, lidocaine tests, preoperative embolization is considered to be a relatively safe procedure. Nevertheless, the risk of severe iatrogenic neurological complications of this method remains up to the present day. Neurological complications occur in approximately $2 \%$ of patients following spinal angiography and local or systemic complications in 4 to $10 \%{ }^{10,34}$

According to Kato et al., we should schedule the spinal tumors surgery on the same day as preoperative embolization. The surgery should be started as early as possible the following day if for any reason it had to be delayed after the embolization. ${ }^{7}$ We excluded patients with postembolization period of more than 3 days from the study for the following reasons. Firstly, there was recruitment of collateral blood flow, a redistribution of blood flow, revascularization of a tumor. Secondly, the gelatin sponge, embolic material used, can be degraded by enzymatic pathways during this period. As a result, we had catastrophic blood loss up to $12000 \mathrm{~mL}$ operating patients with long (more than 3 days) postembolization period.

Hospital stay and cost of surgery is much higher in the groups with embolization because time for evaluation and preparation is usually needed for these patients.

One of the limitations of the current research is that it is a retrospective analysis of patients' records. Another restriction was that we evaluated mixed types of tumors.

Due to the small number of patients we did not divided patients into groups, depending on the extent of soft tissue tumor component (WBB classification layer A). However, tumor extension beyond the vertebral body may increase the risk of excessive intraoperative blood loss. This problem should be considered in the future research.

The overall results showed that the prevention of massive bleeding by local hemostatic agents depends on the type of surgery. Preoperative embolization can be avoided if we perform only palliative decompression in management of hypervascular spinal tumors.

\section{Conclusions}

Local hemostatic agents demonstrated a good control of hemorrhage. The research proves that for patients with hypervascular spinal tumors, who underwent palliative decompression, there is no significant difference between two methods of reducing blood loss. Therefore, we do not see reasons to use expensive and risky procedure of embolization for such patients. While for patients with total spondylectomy preoperative embolization is efficient to reduce intraoperative bleeding.

\section{References}


1. Chen Y, Tai BC, Nayak D, Kumar N, Chua KH, Goy RWL. Blood loss in spinal tumour surgery and surgery for metastatic spinal disease. Bone $J t J$. 2013;95(5):683-688. doi:10.1302/0301-620X.95B5.31270.

2. Pull ter Gunne AF, Cohen DB. Incidence, prevalence, and analysis of risk factors for surgical site infection following adult spinal surgery. Spine (Phila Pa 1976) . 2009;34:1422-1428. doi:10.1097/BRS.0b013e3181a03013.

3. Xing D, Ma J-X, Ma X-L, et al. A methodological, systematic review of evidencebased independent risk factors for surgical site infections after spinal surgery. Eur Spine J. 2013;22:605-15. doi:10.1007/s00586-012-2514-6.

4. Grundy BL, Nash CL, Brown RH. Deliberate hypotension for spinal fusion: prospective randomized study with evoked potential monitoring. Can Anaesth Soc J . 1982;29:452-462.

5. Bilsky MH, Fraser JF. Complication Avoidance in Vertebral Column Spine Tumors. Neurosurg Clin N Am . 2006;17:317-329. doi:10.1016/j.nec.2006.04.007.

6. Choi D, Crockard A, Bunger C, et al. Review of metastatic spine tumour classification and indications for surgery: The consensus statement of the Global Spine Tumour Study Group. Eur Spine J . 2010;19:215-222. doi:10.1007/ s00586-009-1252-x.

7. Kato S, Hozumi T, Takaki Y, Yamakawa K, Goto T, Kondo T. Optimal Schedule of Preoperative Embolization for Spinal Metastasis Surgery. Spine (Phila Pa 1976) . 2013;38(22):1964-1969. doi:10.1097/BRS.0b013e3182a46576.

8. Tomita K, Kawahara N, Baba H, Tsuchiya H, Nagata S, Toribatake Y. Total en bloc spondylectomy for solitary spinal metastases. Int Orthop . 1994;18:291-298. doi:10.1007/BF00180229.

9. Feldman F, Casarella WJ, Dick HM, Hollander BA. Selective intra-arterial embolization of bone tumors. A useful adjunct in the management of selected lesions. Am J Roentgenol Radium Ther Nucl Med . 1975;123:130-139.

10. Prabhu V, Bilsky M. Results of preoperative embolization for metastatic spinal neoplasms. J Neurosurg Spine . 2003;98(Spine 2):156-164. Available at: http://thejns.org/doi/abs/10.3171/spi.2003.98.2.0156. Accessed June 9, 2014.

11. Guzman R, Dubach-Schwizer S. Preoperative transarterial embolization of vertebral metastases. Eur Spine J . 2005:263-268. doi:10.1007/s00586-004-0757-6.

12. Kobayashi K, Ozkan E, Tam A, Ensor J. Preoperative embolization of spinal tumors : variables affecting intraoperative blood loss after embolization . Acta Radiol . 2012;53(8):120314. doi:10.1258/ar.2012.120314.

13. Thiex R, Harris MB, Sides C, Bono CM, Frerichs KU. The role of preoperative transarterial embolization in spinal tumors. A large single-center experience. Spine J . 2013;13:141-149. doi:10.1016/j.spinee.2012.10.031.

14. Light R. The History of Hemostasis,. J Neurosurg Spine . 1945.

15. Chivukula S, Weiner G, Engh J. The early days of hemostasis in neurosurgery. Neurosurg Focus . 2014;36(April):1-5. Available at: http://thejns.org/doi/abs/ 10.3171/2014.1.FOCUS13565. Accessed June 9, 2014.

16. Renkens Jr K, Payner T, Leipzig T. A multicenter, prospective, randomized trial evaluating a new hemostatic agent for spinal surgery. Spine (Phila Pa 1976) . 2001;26(15):1645-1650. Available at: http://journals.lww.com/spinejournal/Abstract/ 2001/08010/A_Multicenter,_.... Accessed June 9, 2014.

17. Schonauer $\mathrm{C}$, Tessitore $\mathrm{E}$. The use of local agents: bone wax, gelatin, collagen, oxidized cellulose. Eur Spine J . 2004;13:89-96. doi:10.1007/s00586-004-0727-z. 
18. Sabel M. The use of local agents : Surgicel and Surgifoam. Eur Spine J . 2004;13:97-101. doi:10.1007/s00586-004-0735-z.

19. Olerud C, Jónsson H, Löfberg AM, Lörelius LE, Sjöström L. Embolization of spinal metastases reduces peroperative blood loss 21 patients operated on for renal cell carcinoma. Acta Orthop . 1993;64:9-12.

20. Manke C, Bretschneider T. Spinal metastases from renal cell carcinoma: effect of preoperative particle embolization on intraoperative blood loss. Am J Neuroradiol . 2001;(May):997-1003. Available at: http://www.ajnr.org/content/22/5/997.short. Accessed June 9, 2014.

21. Wilson MA, Cooke DL, Ghodke B, Mirza SK. Retrospective analysis of preoperative embolization of spinal tumors. AJNR Am J Neuroradiol . 2010;31:656-660. doi:10.3174/ajnr.A1899.

22. Nair S, Gobin YP, Leng LZ, et al. Preoperative embolization of hypervascular thoracic, lumbar, and sacral spinal column tumors: technique and outcomes from a single center. Interv Neuroradiol . 2013;19:377-85. Available at: http://www.ncbi.nlm.nih.gov/pubmed/24070089.

23. Pikis S, Itshayek E, Barzilay Y, et al. Preoperative embolization of hypervascular spinal tumors: current practice and center experience. Neurol Res . 2014;36(6):502-9. doi:10.1179/1743132814Y.0000000361.

24. Berkefeld J, Scale D. Hypervascular spinal tumors: influence of the embolization technique on perioperative hemorrhage. Am J Neuroradiol . 1999;(May):757-763. Available at: http://www.ajnr.org/content/20/5/757.short. Accessed June 9, 2014.

25. Eck JC, Dekutoski MB. En Bloc Resection of Primary Spinal Tumors. Semin Spine Surg . 2009;21:93-98. doi:10.1053/j.semss.2009.03.002.

26. Kato S, Murakami H, Minami T, Demura S. Preoperative embolization significantly decreases intraoperative blood loss during palliative surgery for spinal metastasis. Orthopedics . 2012;35(9):1389-1395. doi:10.3928/01477447-20120822-27.

27. Schmidt R, Rupp-Heim G, Dammann F. Surgical therapy of vertebral metastases. Are there predictive parameters for intraoperative excessive blood loss despite preoperative embolization? Tumori . 2011:66-73. Available at: http://www.tumorionline.it/r.php? $\mathrm{v}=611 \& \mathrm{a}=7141 \& \mathrm{l}=10027 \& \mathrm{f}=$ allegati/00611_2 $\ldots$ (66-73).pdf. Accessed June 9, 2014.

28. Robial N, Charles YP, Bogorin I, et al. Is preoperative embolization a prerequisite for spinal metastases surgical management? Orthop Traumatol Surg Res . 2012;98:536-542. doi:10.1016/j.otsr.2012.03.008.

29. Quraishi NA, Purushothamdas S, Manoharan SR, Arealis G, Lenthall R. Outcome of embolised vascular metastatic renal cell tumours causing spinal cord compression.pdf. Eur Spine J . 2013;22(1):27-32.

30. Perry JW, Montgomerie JZ, Swank S, Gilmore DS, Maeder K. Wound infections following spinal fusion with posterior segmental spinal instrumentation. Clin Infect Dis . 1997;24:558-61 OD - 1997/04/01. Available at: http://www.ncbi.nlm.nih.gov/ entrez/query.fcgi? $\mathrm{cmd}=$ Retrieve $\& \mathrm{db}=$ PubMed\&dop....

31. Fujimaki Y, Kawahara N, Tomita K. How many ligations of bilateral segmental arteries cause ischemic spinal cord dysfunction? An experimental study using a dog model. Spine (Phila Pa 1976) . 2006;31(21):781-789. Available at: http://journals.lww.com/spinejournal/Abstract/2006/10010/How_Many_Ligati.... Accessed June 9, 2014. 
32. Kato S, Kawahara N, Tomita K, Murakami H. Spinal cord blood flow and neurologic function secondary to interruption of bilateral segmental arteries which supply the artery of Adamkiewicz: an experimental study. Spine (Phila Pa 1976) .

2008;33(14):1533-1541. Available at: http://journals.lww.com/spinejournal/Abstract/ 2008/06150/Effects_on_Spinal_Cord_Blood_Flow_and_Neurologic.7.aspx. Accessed June 9, 2014.

33. Murakami H, Kawahara N, Tomita K, Demura S. Does interruption of the artery of Adamkiewicz during total en bloc spondylectomy affect neurologic function? Spine (Phila Pa 1976) . 2010;35(22):1187-1192. Available at: http://journals.lww.com/ spinejournal/Abstract/2010/10150/Does_Interrupti.... Accessed June 9, 2014.

34. Hemingway AP, Allison DJ. Complications of embolization: analysis of 410 procedures. Radiology . 1988;166:669-672.

\section{Disclosures}

The authors declare no financial disclosures.

\section{Corresponding Author}

Nikita Zaborovskii, Vreden Russian Research Institute of Traumatology and

Orthopedics, Spinal Surgery and Oncology, st. A.Baykova, 8, Saint-Petersburg, 195427, Russia.n.zaborovskii@yandex.ru

Copyright (C) 2014 ISASS - International Society for the Advancement of Spine Surgery. To see more or order reprints or permissions, see http://ijssurgery.com. 